\title{
HISTÓRIA DA ENFERMAGEM - O PERÍODO DE DECLÍNIO DA ENFERMAGEM NOS SÉCULOS QUE SE SEGUIRAM A IDADE MÉDIA
}

History of nursing - the period of decline of nursing in the centuries that followed the Medieval Age

História de la Enfermería - el periodo de declive de la enfermería en los siglos que seguieron a la Edad Media

\section{Apresentação}

Alexandre Barbosa de Oliveira'

A História da Enfermagem é uma vasta área interdisciplinar de conhecimento com muitos aspectos a serem abordados, e um deles, que por certo ainda evoca muitos questionamentos e sentimentos de inquietação e perplexidade, é o que envolve o dito "período de declínio da Enfermagem", que ocorreu nos séculos que sucederam à ldade Medieval (476 d.C. - 1453 d.C.). É sobre isso que a Enfermeira Haydée Guanais Dourado discorre no seu artigo (em fac-símile) que foi publicado em julho de 1948, nos Anais de Enfermagem (vol. I, n. 3, p. 113-115).

No texto, um breve panorama é traçado sobre algumas situações que envolveram o exercício da Enfermagem nesse complexo período. Logo de início, a autora chama a atenção para o caráter dual de organização e de desorganização social que caracterizou a ldade Média.

Assim, Haydée Guanais Dourado relaciona as Cruzadas, as Sociedades Feudais, as Ordens Monásticas, como iniciativas aprioristicamente bem-sucedidas para o desenvolvimento da Enfermagem, que reuniam um ideal de cristandade àqueles doentes que necessitassem de cuidados.

Não obstante, em meio à desorganização social (e também administrativa e econômica) advinda das invasões, migrações, aglomerações urbanas, reformas, pestes, secularização e decadência dos hospitais, entre outras, a Enfermagem entra em franco declínio, em virtude do impacto que sofreu com tais transformações sociais. Após esse estágio de desorganização, e algumas décadas depois, a prática da Enfermagem seria facilitada e renovada com a atuação de Florence Nightingale. Um novo momento estava por vir...

Trata-se, pois, de um texto que se reveste de importância histórica em assuntar um período de decadência da Enfermagem, que na época via-se submissa à religião. Com seus progressos, rupturas e mudanças, acabou a Enfermagem submetida ao poder econômico, postura assumida no agora, até que uma nova desorganização social e as necessidades da profissão façam com que seus agentes se empenhem em novos rumos. 


\section{Presentation}

Alexandre Barbosa de Oliveira ${ }^{1}$

The history of nursing is a wide interdisciplinary field of knowledge with many aspects that can be addressed. One of them, which of course also raises many questions and feelings of anxiety and perplexity, is the one that involves the so-called "period of decline of nursing," that took place in the centuries that followed the Medieval Age (476 AD - 1453 AD). This is about what Nurse Haydée Guanais Dourado discusses in her article (facsimile), published in July of 1948 in the Annals of Nursing (Vol. I, No. 3, p. 113-115).

In the text, the author briefly examines certain situations that were involved in the exercise of nursing during this complex period. Right from the start, the author draws attention to the dual characters of social organization and disorganization that characterized the middle Ages.

Haydée Guanais Dourado lists the Crusades, the feudal societies and the monastic orders as successful initiatives for the development of nursing because they meet the ideals of Christianity of the patients who needed care.

However, in the midst of social disorganization (and also administrative and economic) that resulted from the invasions, migrations, urban agglomerations, reforms, pests, decay and secularization of the hospitals, among other reasons, nursing starts an evident decline period due to the impact that such social changes caused. After this stage of disorganization, and some decades later, the practice of nursing would receive compliments, and it renewed activities with the performance of Florence Nightingale. A new time was to come...

This text has historical importance because it analyzes the period of decline of Nursing, which - in those days - was submitted to religion. With the evolution, disruptions and changes of nursing, it became submitted to the economic power, like it is nowadays. And it will remain so until other further social disorganizations or the need of the professionals stimulate the nurses to move into new directions.

\section{Presentación}

Alexandre Barbosa de Oliveira ${ }^{1}$

La historia de la enfermería está conformada por un amplio campo interdisciplinario de conocimiento y cuenta con muchos aspectos que pueden ser analizados. Una de estas vertientes - que por cier to plantea muchas interrogantes, sentimientos de inquietud y perplejidad - es la que envuelve el mencionado "periodo de declive de la enfermería" que tuvo lugar en los siglos que siguieron a la Edad Media (476 d.C. - 1453 d.C.). Es sobre este tema que la enfermera Haydée Guanais Dourado discurre en su articulo (facsímile) que fue publicado en julio de 1948, en los Anales de la Enfermería (Anais de Enfermagem ) vol. I, no. 3, págs. 113-115).

En este texto se esboza un breve panorama de algunas de las situaciones que envolvieron el ejercicio de la Enfermería en este complejo periodo. En primer lugar, la autora subraya el doble carácter de la organización y la desorganización social que caracterizó la Edad Media.

De esta forma, Haydée Guanais Dourado menciona las cruzadas, las sociedades feudales y las órdenes monásticas como iniciativas que tuvieron apriorísticamente éxito en el desarrollo de la enfermería, ya que respondían al ideal del cristianismo de cuidar de los enfermos necesitados de atención.

Sin embargo, en medio de la desorganización social (a su vez administrativa y económica) resultado de las invasiones, las migraciones, las zonas urbanas, las reformas, las plagas, la decadencia y la secularización de los hospitales, entre otros, la enfermería entra en un franco deterioro debido al impacto que provocaron tales cambios sociales. Después de esta etapa de desorganización, y algunas décadas más tarde, la práctica de la enfermería se supera y renueva mediante la actuación de Florence Nightingale. Nuevos tiempos estaban por venir.

Tratase de un texto que está revestido de una importancia histórica porque analiza un periodo de decadencia de la enfermería - que en esta época estaba sometida a la religión. Con el progreso, rupturas y cambios, la enfermería se sometió más tarde al poder económico; postura que persiste hasta nuestros días o hasta que una nueva desorganización social y las necesidades de la profesión lleven a sus profesionales a emprender nuevos rumbos... 


\title{
HISTORIA DA ENFERMAGEM
}

\author{
O período de declínio da Enfermagem nos séculos \\ que se seguiram à Idade Média.
}

HAYDFE GUANAIS DOURADO (\%)

Estudiosos da histôria consideram a Idade Média uma época de organização social e registram um período de desorganização social nos séculos seguintes imediatos.

Desorganização social é desorganizaçäo nas instituiçóes sociais e processa-se quando deixa de existir. entre os membros da sociedade. o consenso social, isto é. o modo de sentir compartilhado, com atitudes e pontos de vista em comum.

A Idade Média é uma éra de consenso social na Europa, éra de aceitaçäo geral dos mesmos mores e das mesmas convicçôes. As Cruzadas reunem todos os europeus para a acão, convictos dos mesmos poritos de vista.

Cuidar do doente do desamparado é ideal de todos os cristãos. Alguns doam seus bens e se recolhem an claustro. 0 tuidado de doentes ocupa, entäo, importante lugar na vida dos monges. Atingiram a um alto gráu de organização social essas sociedades feudais, e a enfermagem prestada aos doentes era um aspecto dessa organizaçāo. Mulheres de educação e fineza chanam a si os mistéres árduos da enfermagem, derivando mérito do exercício da vontade:

Alérn das Ordens Moriásticas, um movimento secular com fundamento religioso surge na Europa Medieval e contribue para grande desenvolvimento da enfermagem. São as Ordens de Cavaleiros Hospitalários. Os Cavaleiros de Säo João de Jerusalém e os Teutônicos constroem hospitais suntuosos, onde cui. dam dos doentes e feridos. Espalham-se desde a Palestina até a Inglaterra.

Entretanto, várias mudanças desorganizam as intituiçōes medievais. Descobertas, inventos, instituiçóes novas são um resultado e por sua vez conduzem-se como forças de transforma. cäo social. Dentre as últimas, as Ordens Seculares das Beguinas, as três Ordens Franciscanas (os Frades, as Clarissas e a

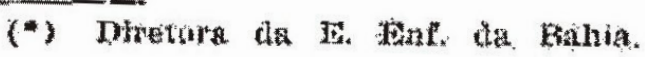


Ordem Terceira) surgem numa tentativa de prestar cuidados de enfermagem às crescentes populações urbanas em condiçōes eco. nômico-sociais precárias. Os mosteiros näo se multiplicam no mesmo rítmo que as populações.

Além dessa desproporção numérica, há, em plena Idade Média, a tendência de se tornarem leigas muitas das instituiçöee que foram criadas ou abrigadas pela Igreja na época de desagre. gação e confusão das invasões bárbaras. A medicina, recebendo seu cabedal de conhecimentos - herança cultural de muitos séculos - preservados nos mosteiros, torna-se leiga e encontra seu lugar nas universidades nascentes. Mais tarde é a vez da educação. Séculos depois registra-se na enfermagem a mesma tendência. Essa transformação não se processou completamente até os nossos dias.

O chamado "período de declínio" na enfermagem é o que se estende desde a Idade Média até a organização das escolas leigas, com Florence Nightingale. O fenômeno que se apresenta como declínio nada mais é do que o tornar-se inadequada uma instituição diante do impacto das transformaçôes sociais. As mudanças sociais que ocasionaram diretamente o declínio da enfermagem foram:

1) Migrações e aglomerações urbancts: - Decorrente de um sistema de produção desconhecido na Idade Média sistema que ocasionou a chamada revolução industrial - grandes massas de população se concentraram nas cidades, substituindo a antiga distribuição por feudos e aldeias. Liverpool, por exemplo, de uma cidade de 4.000 habitantes em 1685 passa a $40.000 \mathrm{em} 1760$, atinge $517.000 \mathrm{em} 1891$ e $803.000 \mathrm{em} \mathrm{1036.} \mathrm{A} \mathrm{superpopu-}$ lação das cidades industriais nascentes, pela imigração de grandes contingentes de populaçôes rurais, é que deve ter causado a superlotação nos leitos dos hospitais, registrada no Hôtel Dieu de Paris e em muitas instituiçóes de assistência na Inglaterra.

2) A enfermagem passa a ser exeraida por serventes. - 0 clima de inquietação mental, de đúvida sôbre principios antes aceitos sem discussão que partiu do humanismo. bem como o interêsse pela vida material, pela inquiriçäo intelectual mais livre, tendem a desviar vocaçóes da vida monástica. Ao mesmo tempo, com o ganhar terreno das idéias materialistas e do secularismo. as ordens religiosas tornaram-se mais rígidas e severas. Decrescendo o número de religiosos reclusos, o cuidado dos 
doentes passou a ser compartilhado por um voluntáriado leigo. Muitas das tarefas antes executadas por religiosas são entregues a serventes empregados pelas congregaçôes que tentam suprir a defieiência de noviças.

Nos paízes protestantes o declínio da enfermagem foi mais acentuado, pela abolição dos mosteiros no século XVI e completa secularizaçăo dos hospitais. As referências ao estado lastimável em que caíram as instituiçōes de assistêneia encontram-se nos relatórios da época e até em obras literárias.

3) A decadencia dos hospitais. - Essa desorganização ocorreu, não só em virtude das causas mencionadas em relaçäo com o declínio da enfermagem, como porque " progresso da medicina não influenciou de pronto o cuídado do doente hospitalizado. Nāo o influenciou porque só no século XVIII os hospitais se tornam campo de estudo clínico par ao ensino médico, entäo prejudicado pelo desinterêsse pela prática e vasio teorismo. O menosprezo pelo uso das mấos e exclusivo prestígio do cultivn intelectual foram fatores importantes dessa demora de progresso. A secularização do hospital também deve ter resultado em enfraquecimento momentâneo da instituiçà̃o.

Em última análise, tôdas as vêzes em que as saciedades passam por grandes mudanças, quando substituem suas instituin cöies, o historiador registra um progresso. Tasse progresso, entretanto, ocorre sempre através de um estágio de desorganização. A desorganização se evidencia quando as necessidades mudam e as instituiçōes se tormam inedequadas.

A enfermagem ainda esta empenhada em mudança. Essas sấo contínuas. Os membros desta, como das outras profissóes, enfrentam dia a dia as contigências de promoverem o ajustamento da profissăo às necessidades sempre em mudança de uma civilizaçāo em marcha. O futuro da enfermagem depende da capacidade, por parte dos membros dessa profiissāo, de efetuarem esse xustamento, guiados pelos princípios básicos da profissão que tem como objetivo servir à humanidade.

\section{BIBLIOGRAFIA:}

Castrglion, A. - History of Medicine.

MuUrors, A. - História da Inglaterra. 